\title{
WHAT ARE CZECH COACHES REALLY DOING? A COMPARISON OF CZECH AND EUROPEAN-WIDE COACHING TRENDS
}

\author{
Honsová, P., Passmore, J., Brown, H.
}

This article aims to explore current coaching practice, and national variations, with a specific focus on the Czech Republic. The data from this study was drawn from a large scale research study involving researchers in 45 European countries and approaching 3000 participants engaged in coaching and mentoring, in a variety of roles: coaches, coach commissioners, mentors and mentor scheme managers. The survey was conducted in 31 languages to enable engagement on equal terms by all participants. The results reveal that Czech coaches read less coaching research, attend fewer coaching seminars and peer groups events than their European peers, while they practice more life-coaching, education and health coaching than their peers in Europe. This suggests that there are some significant differences between Czech and European-wide coaching population. The paper provides a unique insight into the development of coaching in central Europe in comparison with other European states.

Keywords: Coaching trends, European survey, ICF, European Coaching practice, Czech Republic

JEL Classification: M5

\section{Introduction}

Coaching is a widely used managerial developmental intervention. A coach works alongside their client (coachee) using a facilitative style to maximize the potential of the client to reach their stated goals (Whitmore, 2002). In the academic literature coaching has been defined as "a Socratic based future focused dialogue between a facilitator (coach) and a participant (coachee/ client), where the facilitator uses open questions, summarizes and reflections which are aimed at stimulating the self-awareness and personal responsibility of the participant" (Passmore \& Fillery-Travis, 2011).

While a comparatively new practice, it emerged already in the 1980 s in popular form (Wildflower, 2013) and some evidence of coaching use in organizations can be traced back around one hundred years (Trueblood, 1911). In spite of this, little original coaching theory 
has been developed over this period. Coaching's development has instead emerged through praxis, with practitioners drawing on their work in counselling, psychotherapy (e.g. cognitive behavioral, humanistic or solution focused), psychology, such as goal setting theory and self-determination theory (Lock \& Latham, 1984; Deci \& Ryan, 1985) and consulting. These models have been adapted to suit the requirements of coaching practitioners and their clients.

A second challenge facing coaching has been the lack of a scientific evidence base. Practitioners' claims have often run ahead of the science. Only relatively recently have researchers demonstrated through a series of meta-analysis studies (Theeboom et al., 2014; Jones et al., 2015) and systematic literature reviews (Bozer \& Jones, 2018; Athanasoppulou \& Dopson, 2018) the evidential base of coaching and its potential as a tool for supporting behavioral change. Its main benefits lie in enhanced goal attainment (Green et al., 2006), providing a mechanism for stress relief (Gyllenstein \& Palmer, 2005) increasing self-efficacy increase (Moen \& Skaalvik, 2009) and optimizing learning (Passmore \& Rehman, 2012). These individual studies, when drawn together, reveal that overall coaching has an effect size, which is comparable to other organizations' interventions (Theeboom et al., 2014).

Organizations worldwide have widely invested into coaching with the hope of improving clients' goal attainment and well-being or bringing other benefits stated above to the clients. Managers and leaders are being coached all across the globe and often on topics closely related to decision making or management strategies they employ. Therefore, organizations should pay attention to coaching and understand the processes and national trends that emerge to get a better understanding of the intervention their executives engage in.

While the generic literature on coaching remains relatively small, detailed cross cultural comparisons of practice are almost non-existent. Almost no transnational surveys have been published in full, and little work has been done to understand how coaching practices vary between different countries in terms of training, domains of practice, the qualifications of coaches, their commitment to continuous development or their adherence to ethical codes of practices.

This paper aims to explore the trends which emerge in three key themes of coaching research and practice among coaches providing their services in the Czech Republic, and make comparisons with the wider European data pool. 


\section{Theoretical Background}

\subsection{Coaches' background, education and continuous professional development (CPD)}

There is no legal regulation in the Czech Republic, which restricts coaching or protects the use of the term 'coach'. A similar position exists for almost all of Europe, the exception being Italy, which has recently introduced regulation for coaching (Passmore et al., 2018). Instead, most professional coaches operate as members of professional associations, which set standards for practice. The two main international bodies are the International Coach Federation, (ICF) with 30,000 members worldwide and the European Coaching and Mentoring Council (EMCC) with 8000 members worldwide, as of 2018. However, it has been estimated that less than $20 \%$ of individuals who use the 'coaches' as part of the services they offer are members of or accredited by these professional bodies (Passmore, 2011).

There were three coaching organizations in the beginning of 2018 for those who want to either join as a member or become an accredited coach in the Czech Republic. The first of them was the Czech chapter of the International Coach Federation (ICF). The second was the Czech branch of European Mentoring \& Coaching Council (EMCC), a mainly European focused federation. The third was the Czech Association of Coaches (ČAKO). Following a merger between CAKO and the EMCC in spring 2018, there are now two professional bodies. These organizations all offer different competency models, membership conditions and accreditation systems.

Apart from being (or not being) members of different associations, it has been suggested that coaches also differ substantially in their academic education and professional qualifications. Sonesh and her colleagues (2015a) suggested that while some coaches have psychological background, others have limited academic qualifications but lengthy experience in leadership. The value of psychological education has been discussed, with different perspectives offered as to its contribution to coaching outcomes (Bono et al., 2009; Sonesh et al., 2015b). A wide range of different coaching approaches also exist (including behavioral, cognitive behavioral, systemic, gestalt, person centered), which makes coaching a highly individualized intervention.

Coaches are usually trained in programs, which are accredited based on their content and length by the various professional associations, such as the ICF and EMCC.

Continuous professional development (CPD) is an important part of the coaching profession, although as with most other aspects of coaching there is no shared agreement on the framework, obligations, definition or approach (Jepson, 2016). This means CPD can vary from professional activities at work, to reading academic journals, through to structured activities in peer practice groups (Colville, 2016). 


\subsection{Coaches' reflective practice}

As an often personal and intimate relationship, ethical codes have been acknowledged as an important issue in the coaching process (Iordanou et al., 2017). The two main Czech professional associations have both published ethics codes. These codes set out the standards expected from members.

It has been suggested that to be able to think ethically about their work, coaches should reflect on their work (Bachkirova \& Smith, 2015). One method recommended by the EMCC is supervision. Supervision in helping professions traditionally means meetings of individuals or a group of professionals with a qualified supervisor, who helps their clients with challenging topics or develops their skills in the profession (Watkins, 2017). Supervision plays a number of roles, both developmental; helping coaches in their continuous professional development, and supervisory, helping coaches adhere to ethical and professional standards (Hawkins \& Turner, 2017). Supervision thus plays the role of a guaranty for clients that they are receiving a high quality service (Hodge, 2016; Passmore et al., 2018)

In spite of these perceived benefits, there remains a discussion about both the take up and the evidence to support the use of coaching supervision, with a suggestion that take up is often lower than claimed and the evidence in support of supervision as a method for enhancing coaching outcomes or ethical practice is scant (Joseph, 2016).

There are also other methods of reflection apart from formal supervision such as peer practice groups (Kovacs \& Corrie, 2017). These approaches may vary in their focus with a stronger focus on the professional development or providing mutual support.

Some coaches choose to reflect on their practice individually, using video-tapes from their sessions, or using reflective journals (Kovacs \& Corrie, 2017). A wide variety of other methods for reflection are also available, such as action learning, reviewing research, personal CPD and case studies (Passmore et al., 2011).

\subsection{Areas of practice}

Coaching's origins have seen its spread from sport, (Whitmore, 2002) executive, leadership and business coaching (e.g. Ely et al., 2010; Thach, 2002; Wilson, 2007) to schools (Knight, 2007), sales (Rosen, 2008), tertiary education (Van Nieuwerburgh, 2012), medical and health coaching (Palmer et al. , 2003), driver development (Passmore \& Velez, 2012), safety critical environments (Krauesslar et al., 2015), to health and wellbeing (Rogers \& Maini, 2016). The pace and depth of penetration into different sectors has varied between countries, reflecting the diversity of coaching practice across the world. 


\subsection{Research focus and research questions}

In this paper, we focus on the three areas of coaching practice; reflective practice, Continuous Professional Development and areas of practice resulting in three research questions:

1. How do Czech coaches reflect on their practice?

2. How do Czech coaches approach Continuous Professional development?

3. In which areas do Czech coaches practice?

\section{Methods}

The data was gathered from a large-scale survey, undertaken across 51 European countries from Greenland to Belarus and from Norway to Turkey (Passmore et al., 2017). In order to provide maximum access, the project involved international co-operation between European institutions with research leads in each country. Each team made decisions about how their survey could reach the maximum number of coaches, including whether the survey should be translated and which professional membership organizations to partner. In total the survey was translated into 31 languages and over 100 professional organizations and universities agreed to share the research links with their networks. In total, 2898 respondents participated in the research, with 107 being excluded from the sample as they do not practice in Europe.

A total of 106 respondents identified the Czech Republic as the main country of practice. Only one of these respondents has a different country of residence (Slovakia) than the Czech Republic. In this sample, 87 respondents identified themselves as coaches when asked to describe themselves in relation to coaching and mentoring roles.

For comparison, the sample of European coaches was used. The Czech respondents were excluded from the European sample and there were 2209 European coaches from other countries than the Czech Republic.

The same questions were asked in all language and national versions. The Czech version was translated by two researchers and disputable items were discussed and the translation consequently modified. The questionnaire consisted of several parts. The questionnaire was grouped into a series of sections:

- Coaching Practice \& Rates

- Supervision \& reflective practice

- Continuous Professional Development (CPD)

- Areas of practice 
- Conceptual models

- Evaluation

- Contracting for Corporate Coaching assignments

- $\quad$ Ethics \& Contracting

- Commission coaching

The average response time for the questionnaire was 25 minutes.

This paper deals with the results of three sections: supervision and reflective practice, continuous professional development (CPD) and areas of practice.

The questionnaire was shared through professional coaching organizations, (e.g. ICF, EMCC, CAKO) and through professional social networks (such as LinkedIn). As respondents were asked to share the questionnaire with other coaches, using a snowball method, the response rate cannot be determined.

The representativeness of the sample related to coaching organizations affiliation (ICF, EMCC, other organization - CAKO in the case of Czech Republic) was tested in the Czech sample. The results show good representation of the three organizations $\left(\chi^{2}=0.328\right.$, $\mathrm{p}=0.849$, $\mathrm{df}=2$ ). The respondents not being members of any organization were not involved as the population parameter of this category is unknown. More than one third of coaches who are members of the coaching organizations in the Czech Republic participated in our study. Individual coaching organizations provided the number of total organizations' members.

Table 1 | Affiliation to the three coaching organizations in the Czech Republic (as of March 1, 2018)

\begin{tabular}{|l|r|r|r|}
\hline & ICF CZ & EMCC CZ & Other organizations (CAKO) \\
\hline Respondents & 29 & 17 & 15 \\
\hline Total number & 77 & 50 & 49 \\
\hline
\end{tabular}

Sources: ICF (2018), EMCC (2018).

In the sample of Czech coaches ( $\mathrm{N}=87) 49$ women and 38 men participated in the research with only $13 \%$ of the respondents not having a university degree. Most frequently, coaches have post-graduate degree (master's, 70\%), followed by $\mathrm{PhD}(13 \%)$ and undergraduate degree (bachelor's, 3\%).

Respondents answered the question: What is your highest Coaching / Mentoring qualification? Most respondents (30\%) had between 100 and 199 hours of training \& 
study, followed by 400 hours plus of training / study (25\%) and 50 - 99 hours of training \& study (23\%). No respondent had less than 17 hours of training \& study.

Table 2 | Hours of training and study in Czech coaches

\begin{tabular}{|l|r|r|}
\hline & \multicolumn{1}{|c|}{$\begin{array}{c}\text { Absolute } \\
\text { frequency }\end{array}$} & \multicolumn{1}{c|}{$\begin{array}{c}\text { Relative } \\
\text { frequency }\end{array}$} \\
\hline $17-50$ hours of training \& study & 2 & $2 \%$ \\
\hline $50-99$ hours of training \& study & 20 & $23 \%$ \\
\hline $100-199$ hours of training \& study & 26 & $30 \%$ \\
\hline $200-400$ hours days training \& study & 14 & $16 \%$ \\
\hline 400 hours plus of training / study & 22 & $25 \%$ \\
\hline Post-graduate coaching degree (1 year Full time / 2 years PT) & 3 & $3 \%$ \\
\hline Totals & $\mathbf{8 7}$ & $\mathbf{1 0 0 \%}$ \\
\hline
\end{tabular}

As for the experience in the coaching role, most of the respondents had $1-3$ years of experience $(33 \%)$ and $4-7$ years $(30 \%)$. Only one respondent had more than 20 years of experience.

Table 3 | Years of experience of Czech coaches

\begin{tabular}{|l|r|r|}
\hline & \multicolumn{1}{|c|}{$\begin{array}{c}\text { Absolute } \\
\text { frequency }\end{array}$} & \multicolumn{1}{c|}{$\begin{array}{c}\text { Relative } \\
\text { frequency }\end{array}$} \\
\hline Less than 12 months & 4 & $5 \%$ \\
\hline 1 - 3 years & 28 & $33 \%$ \\
\hline 4 - 7 years & 26 & $30 \%$ \\
\hline $8-12$ years & 14 & $16 \%$ \\
\hline 12 - 15 years & 5 & $6 \%$ \\
\hline 16 - 20 years & 8 & $9 \%$ \\
\hline More than 20 years & 1 & $1 \%$ \\
\hline Totals & $\mathbf{8 6}$ & $\mathbf{1 0 0} \%$ \\
\hline
\end{tabular}

\section{Results}

In this part, results of the three following questionnaire sections will be presented:

- Supervision \& reflective practice

- Continuous professional development (CPD)

- Areas of practice

\subsection{Supervision \& reflective practice}

Respondents were asked to answer the question: "What methods do you use to reflect on your practice?" and they were able to choose more than one answer. 
In the Czech sample the most frequent answers contained self-reflection (91\%), reading coaching books $(74 \%)$ and using peer-network (71\%). Formal supervision with a qualified supervisor (45\%), self-support (38\%), mentor (32\%), reading coaching research $(32 \%)$ and co-mentoring (14\%) are also used. No respondent in the Czech nor in the international sample reported not using any method of reflection (see table 4).

The association between Czech and European average (Czech sample excluded) sample was tested in case of all methods of reflection (Pearson $\chi^{2}$ ). The only method of reflection, which showed significantly different in Czech and European samples was 'Reading coaching research' $\left(\chi^{2}=24.95 ; \mathrm{p}<0.001\right)$.

Table 4 | Czech and European results - methods of reflection (percentage, rounded)

\begin{tabular}{|l|r|r|r|r|}
\hline \multicolumn{1}{|c|}{ Method of reflection } & Czech \% & $\begin{array}{c}\text { EU (CZ } \\
\text { excluded) \% }\end{array}$ & \multicolumn{1}{c|}{$\boldsymbol{x}^{2}$} & \multicolumn{1}{c|}{ p-value } \\
\hline Self-reflection & $91 \%$ & $93 \%$ & 0.358 & 0.55 \\
\hline Reading coaching books & $74 \%$ & $80 \%$ & 2.384 & 0.123 \\
\hline Peer network & $71 \%$ & $72 \%$ & 0.012 & 0.914 \\
\hline Formal supervision with a qualified supervisor & $45 \%$ & $46 \%$ & 0.07 & 0.792 \\
\hline Self-support & $38 \%$ & $34 \%$ & 0.51 & 0.475 \\
\hline Mentor & $32 \%$ & $24 \%$ & 3.322 & 0.068 \\
\hline Reading coaching research & $32 \%$ & $59 \%$ & 24.95 & $<0.001$ \\
\hline Co-mentoring & $14 \%$ & $15 \%$ & 0.033 & 0.857 \\
\hline
\end{tabular}

Respondents were also asked to assess how much time they spend on reflective practice per week. The Czech respondents spend in more than half cases (51\%) from 60 to 90 minutes reflecting on their practice per week. The rest spends less than 60 minutes reflecting (22\%), 90 - 120 minutes (20\%), $120-240$ minutes $(6 \%)$ and more than 240 minutes $(2 \%)$. The table 5 shows comparison in time spent reflecting between the Czech and the European sample (Czech sample excluded). The difference between the Czech and the European sample was tested (Mann-Whitney test) and showed no statistical difference in the two samples $(\mathrm{U}=94256.5, \mathrm{p}=0.807)$.

Table 5 | Time spent reflecting on practice per week (in percentage, rounded)

\begin{tabular}{|l|l|l|}
\hline & \multicolumn{1}{|c|}{ CZ } & \multicolumn{1}{|c|}{ EU (CZ excluded) } \\
\hline Less than 60 minutes & $22 \%$ & $26 \%$ \\
\hline $60-90$ minutes & $51 \%$ & $43 \%$ \\
\hline $90-120$ minutes & $20 \%$ & $20 \%$ \\
\hline $120-240$ minutes & $6 \%$ & $8 \%$ \\
\hline more than 240 minutes & $2 \%$ & $4 \%$ \\
\hline
\end{tabular}


Respondents were also asked how much they paid per hour, if they paid for one of these methods of reflection (table 6). The most frequent answer was that the Czech respondents spend less than $€ 50$ per hour on their reflective practice $(33 \%)$, followed by not paying at all (27\%), paying €51-100 (21\%), €101-199 (16\%) and paying €200-399 (4\%). No respondent stated to pay more than $€ 400$ in the Czech sample. The difference between the Czech and the European sample was tested (Mann-Whitney test) and showed no statistical difference in the two samples $(\mathrm{U}=79093, \mathrm{p}=0.859)$.

Table 6 | Money spend per hour on reflecting practice (in percentage, rounded)

\begin{tabular}{|l|l|l|}
\hline & \multicolumn{1}{|c|}{ CZ } & \multicolumn{1}{c|}{ EU } \\
\hline I expect this for free & $27 \%$ & $37 \%$ \\
\hline Less than $€ 50$ per hour & $33 \%$ & $17 \%$ \\
\hline$€ 51-100$ & $21 \%$ & $20 \%$ \\
\hline$€ 101-199$ & $16 \%$ & $18 \%$ \\
\hline$€ 200-399$ & $4 \%$ & $8 \%$ \\
\hline$€ 400-599$ & $0 \%$ & $1 \%$ \\
\hline$€ 600-799$ & $0 \%$ & $0 \%$ \\
\hline$€ 800-999$ & $0 \%$ & $0 \%$ \\
\hline Over $€ 1000$ per hour & $0 \%$ & $0 \%$ \\
\hline
\end{tabular}

Coaches were asked how often they received formal coaching supervision (table 7). About one third of the Czech coaches reported not receiving supervision at all (33\%). Second most repeated answer was that they receive one hour of supervision for every 26-50 hours of coaching with clients (27\%). The rest of the Czech respondents reported 1 hour for 25 hours or less of coaching with clients (20\%), 1 hour for every 51 - 100 hours of coaching with clients $(15 \%)$ and 1 hour of supervisor for more than 100 hours of coaching with clients (6\%). Table 7 and Graph 3 show a comparison with the European sample. The difference between the Czech and the European sample was tested (Mann-Whitney test) and showed no statistical difference in the two samples $(U=88065, p=0.3)$.

Table 7 | Number of supervision hours received per hours spent coaching (chr)

\begin{tabular}{|l|r|r|}
\hline & \multicolumn{1}{|c|}{ CZ } & \multicolumn{1}{c|}{ EU } \\
\hline $1 \mathrm{hr}$ for $25 \mathrm{chr}$ or less & $20 \%$ & $32 \%$ \\
\hline $1 \mathrm{hr}$ for $26-50 \mathrm{chr}$ & $27 \%$ & $19 \%$ \\
\hline $1 \mathrm{hr}$ for $51-100 \mathrm{chr}$ & $15 \%$ & $10 \%$ \\
\hline $1 \mathrm{hr}$ for $100+\mathrm{chr}$ & $6 \%$ & $5 \%$ \\
\hline I don't receive supervision & $33 \%$ & $35 \%$ \\
\hline
\end{tabular}




\subsection{Continuous professional development}

In a following section of the questionnaire, the topic of continuous professional development was examined. Respondents were asked how many hours of CPD should coaches undertake each year (Table 8). Most of the Czech respondents (40\%) thought that coaches should undertake from 16 to 30 hours of CPD each year followed by answers 6 15 hours (24\%), 31 - 60 hours (22\%), more than 60 hours (13\%) and only 1 respondent (approximately 1\%) thought that coaches should undertake less than 5 hours of CPD each year. The difference between the Czech and the European sample was statistically tested (Mann-Whitney test) and was not found to be significantly different ( $\mathrm{U}=91948.5$; $\mathrm{p}=$ $0.591)$.

Table 8 | Number of CPD hours coaches should undertake each year as viewed by Czech and European coaches

\begin{tabular}{|l|r|r|}
\hline & \multicolumn{1}{|c|}{ CZ } & \multicolumn{1}{c|}{ EU } \\
\hline Less than 5 hours & $1 \%$ & $2 \%$ \\
\hline $6-15$ hours & $24 \%$ & $23 \%$ \\
\hline $16-30$ hours & $40 \%$ & $37 \%$ \\
\hline $31-60$ hours & $22 \%$ & $23 \%$ \\
\hline More than 60 hours & $13 \%$ & $16 \%$ \\
\hline
\end{tabular}

Respondents were also asked how they kept up to date in their coaching practice (table 9) and they could choose more than one option. The most frequent answer was that the Czech respondents keep up to date by reading books about coaching (83\%). Respondents also reported to attend professional networking events (63\%), attend short courses in coaching skills (55\%), attend coaching conferences (49\%), attend additional formal coaching training qualifications (41\%), read coaching research $(37 \%)$, participate in coaching webinars (32\%), and attend peer coaching groups (32\%). Only one Czech respondent reported not to use any of the methods mentioned and none of the Czech sample reported to attend a coaching specific graduate program (while 10\% of the European sample attended such a program). The difference between the Czech and the European sample was tested (Pearson $\chi^{2}$, alfa $=0.05$ ) and some significant differences were found. The Czech respondents attend coaching conferences significantly less than European respondents. The Czech coaches also responded to read less research, participate in coaching webinars and attend peer coaching groups. As mentioned, none of the Czech respondents attended a coaching specific graduate program at a university. 
Table 9 | Keeping up to date - Czech and European coaches (in percentage, rounded)

\begin{tabular}{|l|r|l|l|r|}
\hline \multicolumn{1}{|c|}{ Activity } & CZ & EU & \multicolumn{1}{c|}{$\boldsymbol{X}^{2}$} & p-value \\
\hline Reading coaching books & $83 \%$ & $87 \%$ & 1.083 & 0.298 \\
\hline Attending professional networking events (e.g. 'coaching clubs' etc.) & $63 \%$ & $57 \%$ & 1.481 & 0.224 \\
\hline Attending short courses in coaching skills & $55 \%$ & $59 \%$ & 0.444 & 0.505 \\
\hline Attending coaching conferences & $49 \%$ & $64 \%$ & 7.887 & 0.05 \\
\hline Attending additional formal coaching training qualifications & $41 \%$ & $46 \%$ & 0.819 & 0.365 \\
\hline Reading coaching research & $37 \%$ & $69 \%$ & 33.62 & $<0.001$ \\
\hline Participating in coaching webinars & $32 \%$ & $55 \%$ & 17.55 & $<0.001$ \\
\hline Attending a peer coaching group & $32 \%$ & $54 \%$ & 15.34 & $<0.001$ \\
\hline None of the above & $1 \%$ & $1 \%$ & & \\
\hline $\begin{array}{l}\text { Attending a coaching specific graduate program at a university or } \\
\text { business school }\end{array}$ & $0 \%$ & $10 \%$ & & \\
\hline
\end{tabular}

\subsection{Areas of practice}

In the following sections, respondents were asked in what areas they practiced (table 10) and they could choose more than one option again. The Czech respondents answered that they practice in the areas of performance and leadership coaching (84\%), careers coaching $(78 \%)$, life and well-being coaching (67\%), education coaching (46\%), mental health $(46 \%)$, other area $(15 \%)$, medical/health coaching $(14 \%)$ and driver coaching (1\%) respectively. None of the Czech coaches responded to coach in the area of safety coaching, coaching in prisons or with ex-offenders or coaching homeless people. The difference between the Czech and the European (Czech respondents excluded) sample was tested (Pearson $\chi^{2}$ ). The Czech respondents are more significantly involved in coaching in the areas of careers coaching, life and well-being coaching, education coaching and also medical/health coaching.

Table 10 | Areas of practice - Czech and European coaches (in percentage, rounded)

\begin{tabular}{|l|l|l|r|r|}
\hline \multicolumn{1}{|c|}{ Area of practice } & \multicolumn{1}{c|}{ CZ \% } & EU (CZ excluded) $\%$ & \multicolumn{1}{c|}{$\boldsymbol{X}^{2}$} & \multicolumn{1}{c|}{ p-value } \\
\hline Performance \& leadership coaching & $84 \%$ & $79 \%$ & 1.124 & 0.289 \\
\hline Careers coaching & $78 \%$ & $64 \%$ & 6901 & 0.009 \\
\hline Life \& well-being coaching & $75 \%$ & $49 \%$ & 22.96 & $<0.001$ \\
\hline General workplace coaching & $67 \%$ & $65 \%$ & 0.058 & 0.81 \\
\hline Education coaching & $46 \%$ & $19 \%$ & 36.14 & $<0.001$ \\
\hline Mental health & $22 \%$ & $15 \%$ & 3.287 & 0.07 \\
\hline Other & $15 \%$ & $13 \%$ & 0.193 & 0.661 \\
\hline Medical / health coaching & $14 \%$ & $7 \%$ & 5.384 & 0.02 \\
\hline Driver coaching & $1 \%$ & $1 \%$ & & \\
\hline
\end{tabular}




\begin{tabular}{|l|l|l|l|l|}
\hline Safety coaching & $0 \%$ & $1 \%$ & & \\
\hline Coaching in prisons or with ex-offenders & $0 \%$ & $1 \%$ & & \\
\hline Coaching homeless people & $0 \%$ & $1 \%$ & & \\
\hline
\end{tabular}

\section{Discussion}

Our findings will be discussed in relevance to the subthemes explored. Consequently, the limits of the study and the possible future research directions will be identified.

\subsection{Supervision \& reflective practice}

Previous authors agree on the importance of reflecting on the practice (e.g. Bachkirova, 2015; Hay, 2007; Hodge, 2016; McGonagill, 2002; Passmore, 2011). There was not a single respondent not using any form of reflective practice in the Czech (nor in the international) sample. Nevertheless, it is debatable if the reflective practice of the Czech coaching population is sufficient. The most frequently used method of reflection mentioned was "self-reflection". While self-reflection is a useful tool necessary for coaches' practice, when used solely it may lead to self-deception and the development or continuation of poor practice. Self-deception in coaches can involve a range of issues, such as being oblivious to the client's specific case and context, getting lost in the coaching language or influenced by the coach's desires and fears (Bachkirova, 2015). To address these potential pitfalls, supervision can provide a useful mirror to challenge a single perspective (Joseph, 2016). Results and benefits of supervision can vary based on the coach's age, gender or topic they want to discuss (De Haan, 2017). In the Czech sample, less than half $(45 \%)$ of the coaches reported receiving supervision as part of their regular practice.

Yet, our results show inconsistency in the answers regarding supervision. When asked to report how often our participants receive supervision, only one third (33\%) reported not receiving supervision at all. Discrepancies between what coaches think about supervision and what they really do have been found in previous research. While $86 \%$ of coaches in United Kingdom reported that they considered regular supervision important, only $44 \%$ reported they received it (Hawkins \& Schwenk, 2006).

Coaches seem to prefer methods of reflection, which are easier to access and free, such as self-reflection, reading books about coaching or engaging with their peers. The Czech respondents reported reading less coaching research than their international peers. While research might seem too distant a field for many practitioners, academics have argued "that research can provide valuable benefits for practitioners, if coaching is to follow an evidenced base path of professional development. Research aims to identify and define the knowledge base upon which practitioners work" (Passmore \& Fillery-Travis, 2011, p. 72). Research is thus not disconnected from practice, research must inform practice - but to do so, it must be accessible and relevant to practitioners and the issues and challenges they encounter in their practice. 
The lack of interest in coaching research might stem from specific reasons in the Czech context. First of all, most of the coaching research literature is written in English and the Czech-written sources are limited and sometimes outdated, which prevents coaches not fluent in English from reading coaching research.

We asked the participants to assess how much time they spent on reflecting a week. While assessing time spent might be challenging and subject to a potential bias, the Czech coaches show no statistical difference from the European sample.

\subsection{Continuous professional development (CPD)}

$\mathrm{CPD}$ of coaches is a continuous process involving all kinds of activities, such as peer group meetings, online courses, work activities or reading coaching research (Colville, 2016). Previous pioneering research in the coaches' perception of the CPD importance showed that while coaches see CPD as important and critical, they do not always act according to their belief and do not attend CPD activities regularly (Jepson, 2016).

Most of the Czech respondents read coaching books, attend networking events and short coaching courses. Some forms of CPD were less popular in the Czech sample. Reading coaching research, coaching webinars, peer coaching groups $(37 \%, 32 \%$ and $32 \%$ respectively in the Czech sample) and coaching conferences (49\%) showed lower levels of engagement than the wider European sample ( $\mathrm{p}$-values $\mathrm{p}<0.001, \mathrm{p}<0.001, \mathrm{p}<0.001$ and 0.05 respectively).

There is a paradox in this, because when the Czech coaches were asked how many CPD hours coaches should undertake each year, their answers were not significantly different from the European group. Thus, Czech coaches do not differ in the perception of how much CPD is necessary, yet they differ in which activities they engage in.

The coaching market in the Czech Republic might not be large enough to offer enough Czech-language-based opportunities, such as webinars, peer coaching groups or conferences. However the continued growth in coaching, which is likely to be reflected in the Czech environment, suggests this may be a niche which has yet to be filled. On the other hand, CPD needs vary considerably, and further research could enable a better understanding of coaching CPD needs in the Czech Republic.

\subsection{Areas of practice}

The Czech participants practice in many different areas such as leadership \& performance coaching $(84 \%)$, careers coaching $(78 \%)$ or general workplace coaching $(67 \%)$.

The Czech sample differs from the international European one significantly in four disciplines: life and well-being coaching (75\% in the Czech and $49 \%$ in the European sample, $\mathrm{p}<0.001)$, careers coaching $(78 \%$ in the Czech and $64 \%$ in the European sample, $\mathrm{p}=0.009$ ) education coaching (46\% Czech vs $19 \%$ EU sample, p < 0.001) and medical/health coaching (14\% Czech vs. $7 \%$ EU sample, $\mathrm{p}=0.02)$. 
In the case of life-coaching, some potential problems have been discussed, such as a potential overlap with psychotherapy (Grant, 2003), as clients are attracted to coaching as opposed to therapy (Marschal, 2006) or coaches are faced with working with clients with mental health problems (Spence \& Grant, 2005).

It is debatable why Czech coaches offer life-coaching more than their international colleagues. It might be a matter of market maturity compared to some other markets (e.g. United Kingdom), as coaching has grown in popularity mostly in recent years in the Czech Republic and coaching clients might not be aware of potential limitations of seeking interventions not appropriate for their situation or mental health. This hypothesis should be explored further and tested through further research. The same goes for medical/health coaching, which is relatively highly represented in the Czech sample. It is also important to note that some of the coaches responding in this study might have other occupations (e.g. psychologists), so their interventions might be overlapping to a certain degree. Czech psychotherapists typically have around 5 years of psychotherapy training and psychotherapy related pre-graduate education (ČAP, 2018), yet it might be more acceptable for clients to seek a coach than a psychotherapist even when the topic falls down to the range of psychotherapy better.

The topics of career coaching can overlap with general workplace coaching with the focus on themes such as work-life balance, developing specific skills or other career related decisions and issues (Chung \& Gfroerer, 2003). In the European sample, career and general workplace coaching is practiced by a similar number of coaches $(64 \%$ and $65 \%$ respectively). The reason for the discrepancy in the Czech sample (78\% and $67 \%$ respectively) remains unresolved.

\subsection{Limitations and Future research}

The method of the data collection itself involves several pitfalls. As the survey was shared online, we could not determine its representativeness or response rate. However given the nature of the industry and the lack of a homogeneous group, the snowball techniques enabled maximum engagement with the diverse coaching community. When we tested the distribution of the sample compared to the coaching population gathered under professional bodies, the distribution was not statistically different. Nevertheless, the total number of Czech respondents represents another limitation of our study.

Some of the questions asked did not bring us sufficient evidence to draw substantial conclusions. As the answers contain self-reporting, it is possible that some answered were biased due to problems generally connected to self-reported data collection, such as social desirability bias, possible misunderstanding of the items, fixed choices of the items or different standards between respondents. 
Nevertheless, the Czech coaching population has not been given much attention in previous research and our results can serve as a pioneering work into the trends of the Czech coaching market.

Future research should focus on the question of why the trends identified appear in the Czech coaching environment. Some of the future research questions we propose are:

- Why are Czech coaches reluctant to supervision? What are the barriers?

- Why do Czech coaches avoid reading coaching research?

- Why do Czech coaches hesitate to participate in coaching webinars, peer groups or conferences?

- Why do Czech coaches practice in certain coaching areas (life-coaching, health coaching, education coaching) more than their international peers?

As for the nature of these research questions, research methods exploring these themes should also involve qualitative investigation to determine some underlying principles and motives.

\section{Conclusion}

In this study, we explored the differences between Czech and European Coaches in terms of supervision and reflective practice in general, continuous professional development and areas coaches practice in. We found some significant differences between these two populations. In terms of reflective practice, Czech coaches read coaching research significantly less than their European peers. They also reported reading coaching research less as a means of continuous professional development as well as attending conferences, webinars and peer coaching groups less than their European colleagues. They also differ significantly in areas they practice in. Czech coaches practice significantly more in the areas of career coaching, life and well-being coaching, education coaching and medical/health coaching. The reasons for these discrepancies were discussed including the market size, limited volume of research available in the Czech language, limited number of Czech webinars and other unavailable means of education in the Czech language.

The limitations of the paper were mentioned, including the problematic data collection (snowball), self-reporting and sample size. Nevertheless, this researched showed pioneering work into the world of Czech coaching, which has not been explored before and showed some emerging trends and niches the Czech coaching market has. We recommend future research to focus on the reasons the discrepancies between Czech and European coaches emerge, about which we can now only speculate. The next research questions should involve asking why Czech coaches read less coaching research, attend webinars and peer coaching groups less than their European peers and what are the reason Czech coaches differ significantly in the areas they practice in. 


\section{Acknowledgement}

This work was supported by the Internal Grant Agency of the University of Economics,

Prague under Grant IGA F3/96/2017.

\section{References}

Athanasopoulou, A., \& Dopson, S. (2018). A systematic review of executive coaching outcomes: Is it the journey or the destination that matters the most? The Leadership Quarterly, 29(1), 70-88.

Bachkirova, T. (2015). Self-deception in coaches: An issue in principle and a challenge for supervision. Coaching: An International Journal of Theory, Research and Practice, 8(1), 4-19.

Bachkirova, T., \& Smith, C. L. (2015). From competencies to capabilities in the assessment and accreditation of coaches. International Journal of Evidence Based Coaching \& Mentoring, 13(2), 123-140.

Bono, J. E., Purvanova, R. K., Towler, A. J., \& Peterson, D. B. (2009). A survey of executive coaching practices. Personnel Psychology, 62(2), 361-404.

Bozer, G., \& Jones, R. (2018). Understanding the factors that determine workplace coaching effectiveness: a systematic literature review. European Journal of Work and Organizational Psychology, 27(3), 342-361.

ČAP (2018). Česká asociace pro psychoterapii - Ř́ané členství [Czech Association for Psychotherapy - Regular Membership]. Retrieved June 14, 2018, from http://www.czap.cz/o-nas/clenstvi-v-cap/16-radne-clenstvi.

Chung, Y. B., \& Gfroerer, M. C. A. (2003). Career coaching: Practice, training, professional, and ethical issues. The Career Development Quarterly, 52(2), 141152.

Colville, A. (2016). Continuing professional development (CPD) in coaching psychology. Coaching Psychologist, 12(1), 36-38.

De Haan, E. (2017). Large-scale survey of trust and safety in coaching supervision: Some evidence that we are doing it right. International Coaching Psychology Review, 12(1), 37-48.

Deci, E. L., \& Ryan, R. M. (1985). Intrinsic motivation and self-determination in human behaviour. New York: Plenum.

Ely, K., Boyce, L. A., Nelson, J. K., Zaccaro, S. J., Hernez-Broome, G., \& Whyman, W. (2010). Evaluating leadership coaching: A review and integrated framework. The Leadership Quarterly, 21(4), 585-599.

EMCC (2018). European Mentoring and Coaching Council. Retrieved June 22, 2018 from http://emcc-czech.cz/.

Grant, A. M. (2003). The impact of life coaching on goal attainment, metacognition and mental health. Social Behavior \& Personality: An International Journal, 31(3), 253-264. 
Green, L. S., Oades, L. G., \& Grant, A. M. (2006). Cognitive-behavioural, solutionfocused life coaching: Enhancing goal striving, well-being and hope. Journal of Positive Psychology, 1(3), 142-149.

Gyllensten, K., \& Palmer, S. (2005). Can coaching reduce workplace stress? A quasiexperimental study. International Journal of Evidence Based Coaching and Mentoring, 3(2), 75-85.

Hawkins, P., \& Schwenk, G. (2006). Coaching supervision: Maximising the potential of coaching. London: Chartered Institute of Personnel and Development.

Hawkins, P., \& Turner, E. (2017). The rise of coaching supervision 2006-2014. Coaching: An International Journal of Theory, Research and Practice, 10(2), 102-114.

Hay, J. (2007). Reflective practice and supervision for coaches. Maidenhead, Berkshire: McGraw-Hill.

Hodge, A. (2016). The value of coaching supervision as a development process: Contribution to continued professional and personal wellbeing for executive coaches. International Journal Of Evidence Based Coaching \& Mentoring, 14(2), 87-106.

ICF (2018). International Coach Federation Czech Republic. Retrieved June 22, 2018 from https://www.coachfederation.cz/.

Iordanou, I., Hawley, R., \& Iordanou, C. (2017). Values and ethics in Coaching. Hove: Routledge.

Jones, R. Woods, S., \& Guillaume, Y. (2015). The effectiveness of workplace coaching: A meta-analysis of learning and performance outcomes from coaching. Journal of Occupational and Organizational Psychology, 89(2), 249-277.

Jepson, Z. (2016). An investigation and analysis of the continuous professional development and coaching supervision needs of newly qualified and experienced coaches: a small-scale practitioner-based study. Coaching: An International Journal of Theory, Research and Practice, 9(2), 129-142.

Joseph, S. (2016). A review of research into business coaching supervision. Coaching: An International Journal of Theory, Research and Practice, 9(2), 158-168.

Krauesslar, V., Avery, R., \& Passmore, J. (2015). Taking ownership of safety. What are the active ingredients of safety coaching and how do they impact safety outcomes in critical offshore working environments? Journal of Occupational Safety and Ergonomics. 21(1), 39-46.

Knight, J. (2007). Instructional Coaching: A Partnership approach to improving instruction. London: Sage.

Kovacs, L., \& Corrie, S. (2017). Building reflective capability to enhance coaching practice. Coaching Psychologist, 13(1), 4-12.

McGonagill, G. (2002). The coach as reflective practitioner. In C. Fitzgerald \& J. G. Berger (Eds.), Executive Coaching: Practices and Perspectives (pp. 59-88). Palo Alto, CA: Davies-Black. 
Moen, F., \& Skaalvik, E. (2009). The Effect from Executive Coaching on Performance Psychology. International Journal of Evidence Based Coaching \& Mentoring, 7(2), 31-49.

Palmer, S., Tubbs, I., \& Whybrow, A. (2003). Health coaching to facilitate the promotion of healthy behaviour and achievement of health-related goals. International Journal of Health Promotion and Education, 41(3), 91-93.

Passmore, J., \& Velez, M. J. (2012). Coaching Fleet drivers - a randomized controlled trial (RCT) of 'short coaching' interventions to improve driver safety in fleet drivers. The Coaching Psychologist, 8(1), 20-26.

Passmore, J. (2011). Supervision and continuous professional development in coaching. In J. Passmore (Ed.), Supervision in Coaching (pp. 2-9). London: Kogan Page.

Passmore, J., \& Rehman, H. (2012). Coaching as a learning methodology - a mixed methods study in driver development using a Randomized Controlled Trial and thematic analysis. International Coaching Psychology Review, 7(2), 166-184.

Passmore, J., \& Fillery-Travis, A. (2011). A critical review of executive coaching research: a decade of progress and what's to come. Coaching: An International Journal of Theory, Research and Practice, 4(2), 70-88.

Passmore, J., Brown, H., \& Csigas, Z. (2017). The State of Play in Coaching \& Mentoring: Executive Report. Henley: EMCC \& Henley Business School.

Passmore, J., Brown, H., Giuffredi, G., Lombardo, D. et al (2018). Coaching in Italy 2018. Henley: EMCC \& Henley Business School.

Rogers, J., \& Maini, A. (2016). Coaching for helath: Why it works and how to do it. Maidenhead: Open University Press.

Rosen, K. (2008). Coaching Salespeople into Sales Champions: A Tactical Playbook for Managers and Executives. Chichester: Wiley.

Sonesh, S. C., Coultas, C. W., Marlow, S. L., Lacerenza, C. N., Reyes, D., \& Salas, E. (2015a). Coaching in the wild: Identifying factors that lead to success. Consulting Psychology Journal: Practice and Research, 67(3), 189-217.

Sonesh, S. C., Coultas C. W., Lacerenza C. N., Marlow, S. L., Benishek, L. E., \& Salas, E. (2015b). The power of coaching: a meta-analytic investigation. Coaching: An International Journal of Theory, Research and Practice, 8(2), 73-95.

Spence, G. B., \& Grant, A. M. (2005). Individual and Group Life Coaching: Initial Findings from a Randomised, Controlled Trial. In M. Cavanagh, A. M. Grant, T. Kemp, M. Cavanagh (Eds.), Evidence-based coaching, Vol 1: Theory, research and practice from the behavioural sciences (pp. 143-158). Bowen Hills: Australian Academic Press.

Thach, L. (2002). The impact of executive coaching and 360-feedback on leadership effectiveness. Leadership \& Organization Development Journal, 23(4), 205-214

Theeboom, T., Beersma, B., \& Van Vianen, A. E. (2014). Does coaching work? A metaanalysis of the effects of coaching on individual level outcomes in an organizational context. The Journal of Positive Psychology, 9(1), 1-18.

Trueblood, T. C. (1911). Coaching a debating team. Public Speaking Review, 1, 84-85 
Van Nieuwerburgh, C. (2012). Coaching in Education. London: Routledge.

Watkins, C. J. (2017). Convergence in psychotherapy supervision: A common factors, common processes, common practices perspective. Journal of Psychotherapy Integration, 27(2), 140-152.

Wildflower, L. (2013). The hidden history of coaching. Maidenhead: Open University Press.

Whitmore, J. (2002). Coaching for performance: GROWing people, performance and purpose (3rd ed.). Naperville, IL: Nicholas Brealey.

Wilson, C. (2007). Best practice in performance coaching: A handbook for leaders, coaches, HR professionals and organizations. London Philadelphia: Kogan Page.

\section{Authors}

\section{Pavlína Honsová}

Researcher

Department of Managerial Sociology and Psychology

Faculty of Business Administration

University of Economics, Prague

Nám. W. Churchilla 4, 13067 Prague 3, Czech Republic

pavlina.honsova@vse.cz

\section{Jonathan Passmore}

Director of Henley Centre for Coaching and Behavioural Change

Henley Business School

Greenlands, Henley-on-Thames RG9 3AU, United Kingdom

j.passmore@henley.ac.uk

\section{Hazel Brown}

Head of Department

Department of Sport, Exercise and Health

University of Winchester

Sparkford Rd, Winchester SO22 4NR, United Kingdom

hazel.brown@winchester.ac.uk 